\title{
Mobilnost študentov v primerjalni perspektivi: Slovenija in Nizozemska
}

Maruša Hauptman Komotar

\section{Uvod}

Ena najvidnejših dejavnosti visokošolske internacionalizacije je zagotovo mobilnost študentov, ki se jo v Evropi že od leta 1987 precej intenzivno podpira v okviru programa izmenjav Erasmus, v katerem je do danes sodelovalo več kot tri milijone študentov. ${ }^{1}$ Evropa je tudi vodilna svetovna regija, kar zadeva delež dolgoročno mobilnih študentov, ki so vpisani na visokošolske zavode v tujini za celotno obdobje študija. Uspeh programa Erasmus, pa tudi naraščajoči interes neevropskih študentov za študij v Evropi, sta pomembno prispevala $\mathrm{k}$ razvoju politik (internacionalizacije in) mobilnosti v okviru bolonjskega procesa.

S podpisom Bolonjske deklaracije (1999) se je 29 namreč držav Evropskega visokošolskega prostora (v nadaljevanju EVP), vključno s Slovenijo in Nizozemsko, zavezalo h krepitvi mobilnosti študentov, učiteljev, raziskovalcev in administrativnega osebja. V ta namen je bil leta 2009 na leuvenski konferenci opredeljen precej ambiciozen cilj, da bo leta 2020 vsaj $20 \%$ diplomantov iz EVP del svojega študija ali usposabljanja preživelo v tujini (Leuven Communiqué, 2009). Tri leta kasneje je bila v Bukarešti sprejeta strategija Mobility for Better Learning in s tem deset ključnih ukrepov za bolj uravnoteženo mobilnost na institucionalni, nacionalni in nadnacio-

1 Prispevek govori o programu Erasmus, ki se v obdobju 2014-2020 izvaja kot Erasmus+, ki vključuje obstoječe programe EU na področju izobraževanja, usposabljanja, mladine in športa. 
nalni ravni visokega šolstva (Working Group on Mobility, 2012). Na zadnji, pariški ministrski konferenci, pa je bila izpostavljena potreba po ovrednotenju napredka pri doseganju cilja mobilnosti ,20/2020' v EVP (Paris Communiqué, 2018).

Tovrstne navedbe ustvarjajo potrebo po ocenitvi napredka pri izvajanju politik in praks $\mathrm{v}$ mobilnosti študentov $\mathrm{v}$ različnih državah EVP, npr. $\mathrm{v}$ Sloveniji in na Nizozemskem, ki sta le redko v središču primerjalnih analiz. $\mathrm{V}$ tej luči se prispevek osredinja na raziskovalno vprašanje, kakšen poudarek namenjajo mobilnosti študentov nacionalne in institucionalne politike in strategije (internacionalizacije) v slovenskem in nizozemskem visokošolskem prostoru, in na tej podlagi analizira, ali se cilji, opredeljeni v visokošolskih politikah in strategijah (internacionalizacije), tudi uresničujejo $\mathrm{v}$ praksi. V tem okviru pojasnjuje, $\mathrm{v}$ kolikšni meri sta izbrani državi izpolnili glavne bolonjske cilje na področju študentske mobilnosti, na tej osnovi pa s pomočjo primerjalne analize razpravlja tudi o podobnostih in razlikah na tem področju ter o glavnih razlogih za njihov obstoj. V zaključnem delu prispevek poglablja predhodno razpravo s teoretskimi argumenti institucionalnega izomorfizma-sociološke različice novega institucionalizma, saj je razvoj evropskega visokega šolstva $\mathrm{v}$ okviru bolonjskega procesa postavil teorijo novega institucionalizma $\mathrm{v}$ središče zanimanj raziskovalcev visokega šolstva (glej npr. Dobbins, 2008).

Namen prispevka je torej izboljšati razumevanje vloge študentske mobilnosti v internacionalizaciji slovenskega in nizozemskega visokega šolstva, in na tej osnovi prikazati, da se kljub naraščajočemu pomenu, ki ji ga pripisujejo (nad)nacionalne in institucionalne politike in strategije (internacionalizacije) visokega šolstva, tovrstna oblika internacionalizacije v tujini (glej Knight, 2008) v praksi nanaša le na majhen delež mobilnih študentov. Internacionalizacija visokega šolstva je namreč

nameren proces integracije mednarodne, medkulturne ali globalne razsežnosti v namen, funkcije in izvajanje postsekundarnega izobraževanja, da bi izboljšali kakovost izobraževanja in raziskovanja za vse študente in zaposlene in da bi pomembno prispevali k družbi. (de Wit et al., 2015: 29)

\section{Metodologija}

Prispevek izhaja iz doktorske raziskave o internacionalizaciji in zagotavljanju kakovosti v slovenskem in nizozemskem visokem šolstvu (Hauptman 
Komotar, 2018) in se metodološko opira na analizo različnih dokumentarnih virov (npr. teoretska literatura, nacionalne in mednarodne študije, zakonodaja, nacionalni programi visokega šolstva, institucionalne strategije internacionalizacije itd.). Tovrstne vire podpirajo kvantitativni podatki iz nacionalnih in mednarodnih statističnih podatkovnih baz in kvalitativne evidence iz polstrukturiranih intervjujev, ki so bili izvedeni za namene doktorske raziskave med majem in decembrom 2016. V intervjujih so sodelovali predstavniki nacionalnih agencij za internacionalizacijo in programov mobilnosti in/ali ministrstev, pristojnih za visoko šolstvo, vodstvo visokošolskih zavodov (npr. dekani, rektorji), osebje iz uradov za internacionalizacijo oziroma mednarodnih pisarn, neodvisni eksperti itn. Intervjuvanci so bili izbrani namensko, v skladu $\mathrm{z}$ njihovo vlogo in strokovnim znanjem, njihovo število pa je bilo namenoma nižje (skupaj 18, od tega 8 iz Slovenije, 7 iz Nizozemske in 3 iz širšega EVP).

\section{Primer Slovenije}

\section{Mobilnost študentov $v$ kontekstu visokošolskih politik in strategij (internacionalizacije)}

V zadnjih dveh desetletjih so na razvoj politik internacionalizacije (in predvsem (kratkoročne) mobilnosti) v slovenskem visokošolskem sistemu nedvomno vplivali nadnacionalni, zlasti evropski politični procesi (npr. vstop v EU v letu 2004) in razvoj evropskega visokega šolstva v okviru bolonjske reforme. Poleg podpisa Bolonjske deklaracije (1999) je bila npr. v Sloveniji v novembru $1999 \mathrm{~s}$ spremembami visokošolske zakonodaje uveljavljena tudi določba, da $\mathrm{z}$ vstopom države $\mathrm{v}$ EU državljani njenih držav članic pridobijo pravico do izobraževanja na slovenskih visokošolskih ustanovah pod enakimi pogoji kot veljajo za slovenske državljane (Zakon o spremembah in dopolnitvah Zakona o visokem šolstvu, 1999: 2. člen). Leta 2002 je bil sprejet (prvi) nacionalni program visokega šolstva, ki je izpostavil pomen mednarodnega institucionalnega sodelovanja v programih izmenjav EU (npr. Socrates-Erasmus), regionalnih programih (npr. CEEPUS oziroma Central European Exchange Program for University Studies) in izgradnje EVP (Ministrstvo za šolstvo, znanost in šport, 2002). Leto kasneje (2003) je bil ustanovljen tudi Center Republike Slovenije za mobilnost in evropske programe izobraževanja in usposabljanja (CMEPIUS), ki od leta 2006 deluje kot nacionalna agencija, pristojna za izvajanje programov mobilnosti in dvostranskih sporazumov. 
Tudi aktualna Resolucija o nacionalnem programu visokega šolstva za obdobje 2011-2020 je, v skladu s poudarki Evropske komisije (2013) o razvoju celovitih strategij internacionalizacije in s tem mednarodne mobilnosti, internacionalizacije kurikula in strateških partnerstev, poudarila potrebo po sprejetju nacionalne strategije internacionalizacije, ki je bila objavljena v letu 2016 (glej Ministrstvo za izobraževanje, znanost in šport, 2016a). Slednja opredeljuje mednarodno mobilnost kot ključno za razvoj visokokakovostnega visokošolskega sistema, s tem pa tudi odprtost za sodelovanje in izmenjave znotraj in zunaj EVP (ibid.). To pomeni, da naj bi študij na slovenskih visokošolskih zavodih do leta 2020 zaključilo vsaj $10 \%$ mednarodnih študentov, 20 \% slovenskih diplomantov pa naj bi sodelovalo v programih izmenjav v tujini (Ministrstvo za visoko šolstvo, znanosti in tehnologijo, 2011).

$\mathrm{Na}$ slovenskih visokošolskih zavodih je (študentska) mobilnost prav tako v ospredju institucionalnih strategij internacionalizacije, ki pa so bile sprejete predvsem na ravni univerz, na ostalih visokošolskih zavodih pa so te pogosto del širših razvojnih visokošolskih strategij. Univerza v Ljubljani npr. opredeljuje strateški cilj do leta 2020 povečanja študentskih izmenjav za tretjino in števila tujih študentov za četrtino (Univerza v Ljubljani, 2014), medtem ko Univerza na Primorskem izpostavlja, da bo do študijskega leta 2020/21 med celotno študentsko populacijo desetina tujih študentov (Univerza na Primorskem, 2014).

Ker se torej mobilnost študentov v (nad)nacionalnih in institucionalnih politikah in strategijah (internacionalizacije) dojema kot ključna dejavnost za višjo kakovost (internacionalizacije) slovenskega visokošolskega prostora, velja v nadaljevanju preučiti, v kolikšni meri se opredeljeni cilji politik in strategij na tem področju tudi dejansko uresničujejo v praksi.

\section{Mobilnost študentov $v$ praksi}

V okviru dolgoročne mobilnosti se število tujih študentov, vpisanih na slovenske visokošolske ustanove, iz leta v leto povečuje. Kot poroča Statistični urad Republike Slovenije (v nadaljevanju SURS), je bilo v študijskem letu 2018/19 na slovenske visokošolske zavode vpisanih 5,079 tujih študentov s stalnim prebivališčem v tujini (SURS, 2019), kar predstavlja 7,7 \% celotne študentske populacije. V tem študijskem letu jih je kar tri četrtine (75 \%) izviralo iz držav nekdanje Jugoslavije, in sicer iz Hrvaške (20.8 \%), Bosne in Hercegovine $(18,5 \%)$, Severne Makedonije (18,5 \%), Srbije (10,9 \%), Kosova $(3,6 \%)$ in Črne Gore (2,7 \%), izmed drugih držav pa so imele v tem letu naj- 
večji delež študentov na visokošolskem študiju v Sloveniji Italija (5,9\%), Ruska federacija $(2,9 \%)$ in Ukrajina $(1,4 \%)$ (SURS, 2019). To pomeni, da Slovenija (še vedno) ni prednostna študijska destinacija za študente iz zahodnih (evropskih) držav, saj le četrtina ( $25 \%$ ) vseh dolgoročno mobilnih študentov izvira iz držav, ki niso nekdanje jugoslovanske republike. (Nad)nacionalno strateško merilo desetine vpisanih tujih študentov na slovenskih visokošolskih ustanovah se torej v letu 2020 ni uresničilo v praksi.

Po drugi strani je bilo po podatkih Unescovega inštituta za statistiko $(\mathrm{UIS})^{2}$ na tuje visokošolske zavode v letu 2019 vpisanih tudi 3,157 slovenskih študentov; njihove prednostne ciljne države so bile v tem letu Avstrija $(24,9 \%)$, Nemčija (13,5\%) in Združeno kraljestvo (12,4 \%), ki so skupaj gostile približno polovico $(50,8 \%)$ vseh slovenskih študentov na terciarnem študiju v tujini (UIS, 2019). Vendar pa je bilo v tem letu v Sloveniji dolgoročno mobilne le 3,1\% celotne terciarne študentske populacije (UIS, 2019), glavne študijske destinacije pa, z izjemo Hrvaške in Srbije, niso bile države Zahodnega Balkana, temveč zlasti starejše članice EU-ja.

Na področju kratkoročne mobilnosti so $\mathrm{v}$ Sloveniji v študijskem letu 2014/15 prihajajoči študenti iz tujine, ki so sodelovali v programih izmenjav, predstavljali 2,9\% celotne populacije študentov, od tega jih je (kar) 2,7 \% sodelovalo v programu Erasmus (Ministrstvo za izobraževanje, znanost in šport, 2016, v Hauptman Komotar, 2018). Na slovenskih visokošolskih ustanovah so bili v tem letu najštevilčnejši španski, turški in češki Erasmus študentje (European Commission, 2017), torej so bile njihove glavne izvorne države tiste iz Srednje in Vzhodne Evrope ter starejše članice EU-ja.

V programih mobilnosti v tujini je v tem letu sodelovalo (le) 3,4 \% slovenskih študentov, kar pomeni relativno rast njihovega odstotnega deleža od leta 2009/10 dalje, ko se je za izmenjave v tujini odločilo le 1,4 \% domačih študentov (Ministrstvo za izobraževanje, znanost in šport, 2016, v Hauptman Komotar, 2018). V letu 2015 so v okviru programa Erasmus, v katerem je sodelovala velika večina prihajajočih študentov (2,5\%), del študija najpogosteje preživeli na nemških, španskih in avstrijskih visokošolskih ustanovah (European Commission, 2017), torej v državah Zahodne Evrope. Delež domačih kratkoročno mobilnih študentov je (bil) torej precej pod zadanim strateškim ciljem ,20/2020', ki je bil opredeljen tako na ravni EVP kot tudi na ravni slovenskega visokošolskega sistema (glej Leuven Communiqué, 2009; Ministrstvo za visoko šolstvo, znanosti in tehnologijo, 2011). V akcij-

2 Na voljo so podatki o terciarnem izobraževanju (srednješolsko in visokošolsko izobraževanje, ISCED 5-8). 
skem načrtu izvajanja nacionalne strategije internacionalizacije je bil v letu 2018 sicer opredeljen bolj realističen strateški cilj $5 \%$ kratkoročno mobilnih študentov do leta 2020 (Ministrstvo za izobraževanje, znanost in šport, 2019), ki pa, kot kaže, v tem letu ne bo uresničen.

V Sloveniji je tako na področju kratkoročne študentske mobilnosti sorazmerje med deležem prihajajočih in odhajajočih mobilnih študentov bolj uravnoteženo kot v okviru dolgoročne mobilnosti, medtem ko je skupni delež prihajajočih in odhajajočih, diplomsko in kreditno mobilnih študentov v slovenskem visokem šolstvu pa je še vedno relativno nizek, gibanja v mobilnosti pa nizko intenzivna. Na slednja namreč vpliva tudi (stalni) upad v številu oziroma deležu vpisanih študentov v visokošolsko izobraževanje v Sloveniji.

\section{Primer Nizozemske}

\section{Mobilnost študentov $v$ kontekstu visokošolskih politik in strategij (internacionalizacije)}

V sredini devetdesetih let preteklega stoletja so nizozemski oblikovalci visokošolskih politik pričeli poleg sodelovanja v okviru programov izmenjav na ravni EU izpostavljati tudi prihod neevropskih študentov, ki plačujejo šolnine. V zadnjem desetletju je na Nizozemskem ta "preusmeritev na visoko šolstvo kot izvozno blago« (de Wit, 2012: 437) postala bolj očitna, saj je nizozemska vlada začela intenzivneje poudarjati strateški cilj postati eno izmed petih vodilnih, na znanju temelječih ekonomij v globalnem merilu, internacionalizacijo visokega šolstva pa je opredelila kot ključno za dosego tega cilja. V letu 2014 sta tudi združenji nizozemskih univerz in univerz uporabnih znanosti predstavili svojo vizijo internacionalizacije in v skladu s tem pozvali k vnovični uvedbi nacionalnega programa štipendiranja mednarodne mobilnosti, ki je bil zaradi varčevalnih ukrepov v letu 2011 ukinjen (VSNU in VH, 2014). Kmalu zatem je tudi pristojni minister izrazil podporo vnovični vzpostavitvi programa štipendiranja, ki bi pritegnil najbolj talentirane študente iz držav zunaj Evropskega gospodarskega prostora in bi hkrati spodbudil študij domačih študentov v tujini (Ministry of Education, Culture and Science, 2014). Leta 2015 je v dolgoročnem strateškem programu o visokošolskem izobraževanju in raziskovanju (2015-2025) prav tako poudaril, da so mednarodni študenti »resnična dodana vrednost našemu izobraževanju in nizozemski ekonomiji znanja«, saj ni zanemarljivo, da 
ima »lahko vhodna mobilnost neto pozitiven učinek v višini 740 milijonov EUR letno" (Ministry of Education, Culture and Science, 2015: 12).

Tudi na institucionalni ravni je npr. Univerza Twente v svoji strategiji internacionalizacije navedla strateški cilj povečanja števila mednarodnih študentov, vključenih $\mathrm{v}$ magistrske študijske programe, iz 300 na 640 do leta 2020 (University of Twente, 2015), zadala pa si je tudi cilj, da bo $» 75$ odstotkov vseh dodiplomskih študentov v tujini pridobilo izkušnje v obsegu najmanj 15 kreditnih točk« (Intervju 2, 31. 5. 2016).

V nadaljevanju se tako prispevek osredinja na gibanja v študentski mobilnosti v nizozemskem visokošolskem prostoru, s tem pa zagotavlja ustrezno primerjalno iztočnico analize gibanj $\mathrm{v}$ mobilnosti študentov $\mathrm{v}$ obeh izbranih državah (in tudi na ravni EVP), čemur se posveča v nadaljnji razpravi.

\section{Mobilnost študentov $v$ praksi}

Kot poroča nizozemska organizacija za internacionalizacijo v izobraževanju Nuffic, je bilo v akreditirane študijske programe javnih visokošolskih zavodov v študijskem letu 2018/19 vpisanih 85,955 mednarodnih študentov, ki so predstavljali $11,5 \%$ celotne študentske populacije v nizozemskem visokošolskem izobraževanju (Nuffic, 2019a). To pomeni, da je v tem letu največ dolgoročno mobilnih študentov izviralo iz sosednje Nemčije (26,3\%), Italije $(5,6 \%)$ in Kitajske $(5,3 \%)$, in da se prav tako povečuje število mednarodnih študentov iz nekaterih južnih in vzhodnoevropskih držav (Bolgarija, Grčija, Romunija) oziroma iz držav z uradi NESO (nizozemski uradi za podporo izobraževanju), kot sta Indija in Indonezija (Nuffic, 2019a).

Po drugi strani je bilo v terciarno izobraževanje v tujini v študijskem letu 2016/17 vključenih 18,483 nizozemskih študentov oziroma 2,1 \% celotne terciarne študentske populacije (UIS, 2019). Belgija (27,4 \%), Združeno kraljestvo (19,1 \%) in ZDA (11,2 \%) so skupaj gostile nekoliko manj kot dve tretjini $(57,7 \%)$ vseh nizozemskih študentov na terciarnem študiju v tujini, med ostalimi študijskimi destinacijami pa so v tem letu prevladovale starejše članice EU-ja (UIS, 2019). Razmerje med deležem prihajajočih in odhajajočih dolgoročno mobilnih študentov je torej na Nizozemskem precej neuravnoteženo, zaradi česar gre za državo uvoznico, saj je izhodna stopnja dolgoročne mobilnosti bistveno nižja.

V okviru kratkoročne mobilnosti v programu Erasmus je na Nizozemskem v letu 2016/17 sodelovalo 12,755 študentov, izmed katerih so bili najštevilčnejši nemški, španski in francoski študenti, njihove glavne izvorne dr- 
žave pa, z izjemo Poljske in Turčije, starejše članice EU-ja (Italija, Združeno kraljestvo, Belgija) (Nuffic, 2019b). V tem letu je del študija v tujini preživelo tudi 13,107 nizozemskih Erasmus študentov, in sicer najpogosteje v Španiji, Združenem kraljestvu in Nemčiji (ibid.), kar pomeni, da so zahodnoevropske države v tem letu gostile največ nizozemskih Erasmus študentov.

$\mathrm{V}$ nasprotju s precej neuravnoteženim razmerjem med številom oziroma deležem prihajajočih in odhajajočih dolgoročno mobilnih študentov je to razmerje na področju kratkoročne mobilnosti precej bolj uravnoteženo, saj je število prihajajočih in odhajajočih Erasmus študentov skoraj enako (12,755 in 13,107 v letu 2016/17) (glej Nuffic, 2019b).

\section{Slovenija in Nizozemska $\mathrm{v}$ primerjalni perspektivi}

\section{Mobilnost študentov v primerjalnem kontekstu visokošolskih politik in strategij}

Primerjalna analiza nacionalnih in institucionalnih politik in strategij (internacionalizacije) $\mathrm{v}$ slovenskem in nizozemskem visokošolskem sistemu pokaže, da obe državi prednostno izpostavljata povečanje števila oziroma deleža dolgoročno in kratkoročno mobilnih študentov, zaradi česar se mobilnost pogosto dojema kot »oznaka za internacionalizacijo visokega šolstva« (Teichler, 2010: 267). Za razliko od Nizozemske, kjer različni strateški dokumenti vse bolj poudarjajo pomen rekrutiranja mednarodnih študentov kot ključnega za nizozemsko ekonomijo znanja (glej npr. Ministry of Education, Culture and Science, 2015), se v Sloveniji izpostavlja, da mednarodna mobilnost prispeva $k$ večji kakovosti (internacionalizacije) visokega šolstva (Ministrstvo za izobraževanje, znanost in šport, 2016). Internacionalizacija slovenskega visokega šolstva torej ni instrument za povečanje nacionalne konkurenčne prednosti v svetovnem merilu in tudi ekonomski motivi zanjo so prisotni v precej manjšem obsegu kot v nizozemskem primeru, kjer je »vlada - tako kot v številnih drugih državah - uvedla polne šolnine za ne-EU študente, [in] to je ekonomski nagib. To je razumljivo, ker zakaj bi davkoplačevalci financirali tovrstno mobilnost« (Intervju 3, 20. 6. 2016). Po drugi strani je npr. slovenski intervjuvanec v zvezi s tem poudaril naslednje:

Ko smo vstopili v OECD, so nam zelo jasno rekli: 'zakaj nimate šolnin? [...] Če boste hoteli zagotoviti takšno kakovost, kot jo imate sedaj v visokem šolstvu, je država s tem gospodarskim potencialom prešibka, da to vzdrži. Vi rabite šolnine.' /.../ In kako 
bomo imeli potem internacionalizacijo? Internacionalizacija je potem za povrh, za počitnice - takrat se greš internacionalizacijo, in to ni prav. (Intervju 5, 7. 9. 2016)

Čeprav se mobilnost $\mathrm{v}$ obeh državah dojema kot glavna dejavnost internacionalizacije visokega šolstva ( $\mathrm{v}$ tujini), je $\mathrm{v}$ nizozemskem primeru "več pozornosti namenjeno vključitvi mobilnosti $\mathrm{v}$ kurikul in internacionalizacijo doma " (Intervju 3, 20. 6. 2016). Slednje oblike internacionalizacije pa institucionalni dokumenti ne dojemajo kot alternativo mobilnosti, temveč kot dve komplementarni področji (van Gaalen et al., 2014: 3), medtem ko je v Sloveniji na večini slovenskih visokošolskih zavodov »internacionalizacija doma še zmeraj v povojih" (Klemenčič in Flander, 2013: 144). Ta ,domača razsežnost visokošolske internacionalizacije je sicer vredna nadaljnje obravnave, vendar pa se prispevek v nadaljevanju posveča primerjavi gibanj $\mathrm{v}$ dolgoročni in kratkoročni mobilnosti $\mathrm{v}$ slovenskem in nizozemskem visokošolskem prostoru, $s$ čimer primerjalno ponazori obstoječe prakse na področju dolgoročne in kratkoročne mobilnosti študentov, s tem pa tudi odzive obeh visokošolskih sistemov na prevladujoče visokošolske politike in strategije (internacionalizacije).

Mobilnost študentov $v$ slovenskem in nizozemskem visokem šolstvu $v$ praksi

V okviru dolgoročne mobilnosti je bil v letu 2018/19 delež tujih študentov s stalnim prebivališčem $\mathrm{v}$ tujini, ki so bili vpisani na slovenske visokošolske zavode 7,7-odstoten, medtem ko so na Nizozemskem v tem letu mednarodni študenti predstavljali več kot desetino $(11,5 \%)$ celotne visokošolske študentske populacije (Nuffic, 2019a). Nizozemska je namreč del elitne deseterice držav $\mathrm{z}$ najštevilčnejšo mednarodno študentsko populacijo, ki po podatkih OECD-ja zaseda šesto mesto, za Novo Zelandijo, Združenim kraljestvom, Švico, Avstrijo in Avstralijo (OECD, 2017). V obeh primerih več kot petina dolgoročno mobilnih študentov in tujine izvira iz sosednje države; v slovenskem primeru iz Hrvaške (20,8 \%), v nizozemskem pa iz Nemčije (26,3 \%).

To pomeni, da so gibanja $\mathrm{v}$ študentski mobilnosti podvržena nekaterim kontekstualno specifičnim vplivom, saj v Sloveniji kar tri četrtine vseh tujih študentov zastopajo tisti iz bivših jugoslovanskih republik (SURS, 2019). Ker želi Slovenija postati primer dobre prakse na področju regijske mobilnosti, tudi ukrepi na ravni sistema podpirajo enake pogoje šolnin za študente iz te regije kot veljajo za slovenske študente ali tiste iz EU (Mini- 
strstvo za visoko šolstvo, znanost in tehnologijo, 2011). Po drugi strani je visok delež nemških študentov na nizozemskih visokošolskih ustanovah odraz izvajanja pravila numerus clausus, ki omejuje pravico do vpisa na nekatere študijske programe (npr. medicina, veterina) na nemških visokošolskih zavodih.

Primerjalno gledano je torej delež domačih študentov na študiju v tujini v obeh državah nižji, kar je še posebej očitno v nizozemskem primeru, saj se vseskozi giblje okrog $2 \%$ celotne terciarne študentske populacije, to pa je nižje kot v slovenskem primeru (3,2 \%) (UIS, 2019). Tako v Sloveniji kot na Nizozemskem sta glavni študijski destinaciji domačih dolgoročno mobilnih študentov sosednji (zahodnoevropski) državi, in sicer Avstrija (v slovenskem primeru) in Belgija (v nizozemskem primeru). Prav tako je v obeh primerih Združeno kraljestvo ena izmed treh osrednjih ciljnih držav, ki skupaj z Nemčijo in Francijo privabi več kot polovico (55\%) vseh dolgoročno mobilnih študentov v Evropi (European Commission et al., 2018). V državah EVP so torej splošna povprečja v študentski mobilnosti močno pogojena $\mathrm{z}$ gibanji $\mathrm{v}$ teh treh študijskih destinacijah (de Wit, 2012). To tudi pomeni, da je razmerje med deležem prihajajočih in odhajajočih dolgoročno mobilnih študentov v nizozemskem primeru (precej) bolj neuravnoteženo kot v primeru Slovenije (približno 6:1, v Sloveniji približno 1: 0,7), zaradi česar je Nizozemska pogosto označena za državo ,neto uvoznico mednarodnih študentov $\mathrm{z}$ višjim deležem prihajajočih študentov, Slovenija pa za državo $\mathrm{z}$ relativno uravnoteženimi gibanji $\mathrm{v}$ dolgoročni mobilnosti študentov, ki pa so nizko intenzivna (European Commission et al., 2018).

Nadalje, kratkoročno mobilnost se $\mathrm{v}$ obeh državah najpogosteje izvaja v okviru programa Erasmus; v okviru programa so bili npr. na slovenskih visokošolskih zavodih v letu 2014/15 najštevilčnejši španski študentje, medtem ko so bili na Nizozemskem v letu 2016/17 najštevilčnejši nemški študentje. Nemčija je tudi gostila največje število slovenskih Erasmus študentov, med nizozemskimi pa je bilo najbolj priljubljeno Združeno kraljestvo. V tem letu je del svojega študija na Nizozemskem prav tako preživelo 96 Erasmus študentov iz Slovenije, 49 nizozemskih študentov pa je sodelovalo $\mathrm{v}$ tem programu na slovenskih visokošolskih ustanovah.

Gibanja v mobilnosti študentov torej ne odražajo retorike (nad)nacionalnih in institucionalnih strateških dokumentov, saj je »(v) večini slovenskih visokošolskih zavodov /.../ program Erasmus le ,dodatna oblika' mednarodnega sodelovanja (Klemenčič in Flander, 2013: 144). Po drugi strani obstajajo na Nizozemskem »številne institucije, ki se osredotočajo na mo- 
bilnost, in obstajajo tudi številne institucije, ki se osredotočajo na samo internacionalizacijo, tako da so [njihove strategije] celovitejše« (Intervju 1, 30. 5. 2016).

\section{Zaključki}

Dosedanja primerjalna razprava zagotavlja tudi ustrezno izhodišče za obravnavo podobnosti in razlik $\mathrm{v}$ izvajanju politik in praks na področju mobilnosti študentov med različnimi članicami bolonjskega procesa. Kot poroča raziskava Trends 2015, 66 \% sodelujočih visokošolskih ustanov iz EVP dojema študentsko mobilnost kot glavno dejavnost, ki prispeva $\mathrm{k}$ izboljšanju poučevanja in učenja (Sursock, 2015), saj »se institucije odločajo za veliko enostavnih oblik internacionalizacije, ker so te vidne (Intervju 1, 30. 5. 2016). Toda »[z]aradi pomena, ki ga večina nacionalnih vlad $v$ javnih izjavah pripisuje mobilnosti študentov in osebja, je presenetljivo, kako zelo malo jih je razvilo celovite in sistematične politike mobilnosti« (Teichler et al., 2011: 8). Države podpisanice bolonjskega procesa namreč ambiciozno izpostavljajo potrebo po preseganju leuvenskega cilja ,20/2020, vendar pa predstavlja njegova uresničitev (še vedno) znaten izziv tako za Slovenijo kot za mnoge druge, zlasti srednje-, vzhodno- in južnoevropske države (European Commission et al., 2018). Na ravni EVP je namreč izmed 32 držav 21 držav bodisi ,neto izvoznic' (predvsem tiste iz Vzhodne Evrope) ali ,neto uvoznic' (predvsem tiste iz Zahodne in Severne Evrope) (Teichler et al., 2011).

Države bolonjskega procesa, vključno s Slovenijo in Nizozemsko, si torej še vedno (pre)pogosto prizadevajo za kvantiteto na račun kvalitete, saj "nejasno podpirajo mobilnost kot zaželeno dejavnost in sprejemajo pristop ,the more the merrier " ${ }^{3}$ (Teichler et al., 2011: 8). Ker se v Sloveniji internacionalizacijo in s tem mobilnost (študentov) razume tudi kot prenos nadnacionalnih politik (na ravni EU in EVP) v visokošolskih sistem, je eden izmed slovenskih intervjuvancev $\mathrm{v}$ zvezi s tem izpostavil:

Ko je neka strategija ali neki delovni program sprejet na ravni EU, potem se nanj odzovemo /.../. Ko so na voljo sredstva $\mathrm{v}$ EU programih, kot je zdaj recimo Erasmus+, se bo našlo toliko in toliko institucij, ki se bodo na to odzvale /.../, zato smo počasni. (Intervju 4, 29. 6. 2016) 
Tovrstne navedbe je moč teoretsko podkrepiti s predpostavkami institucionalnega izomorfizma, sociološke različice novega institucionalizma (glej DiMaggio in Powell, 1983; Hall in Taylor, 1996), ki se v (primerjalnih) študijah visokega šolstva pogosto uporablja za pojasnjevanje zbliževanja med visokošolskimi pojavi (npr. Dobbins, 20o8). Institucionalni izomorfizem namreč trdi, da so »nacionalne države [...] bolj izomorfne, kot bi napovedala večina teorij, in se spreminjajo bolj uniformno, kot je splošno priznano « (Meyer et al. 1997: 173). V tem kontekstu naj bi tudi vključitev držav v bolonjski proces spodbudila »razvoj visoke ravni primerljivosti, združljivosti in izmenjave med visokošolskimi institucijami ter sistemi evropskega visokošolskega prostora « (Evropska komisija, 2013: 2), še posebej v okviru programov mobilnosti (študentov), saj so se članice bolonjskega procesa zavezale k uresničitvi cilja petine domačih študentov do leta 2020 (Leuven Communiqué, 2009).

Zaradi sklicevanja na homogenost pa je ena vidnejših omejitev institucionalnega izomorfizma neosredotočenost na specifična lokalna okolja (DiMaggio in Powell, 1991), s čimer spregleda možen obstoj raznolikosti $\mathrm{v}$ nacionalnih in institucionalnih (lokalnih) odzivih organizacij in akterjev na visokošolski razvoj na mednarodni (tj., globalni in regionalni) ravni (Vaira, 2004). Mednarodna mobilnost (študentov) je namreč visokošolski pojav s soodvisnimi odnosi, ki presegajo usmeritev na izključno nacionalno razsežnost visokega šolstva, npr. nacionalno državo oziroma visokošolski sistem. Naslednja, sicer bolj splošna pomanjkljivost teorije novega institucionalizma je nepriznavanje institucij kot "produkta človeških dejanj « (DiMaggio in Powell, 1991: 28) in s tem obstoja različnih prepričanj in navzkrižja interesov med različnimi visokošolskimi akterji. Različne interesne skupine namreč različno odgovarjajo na vprašanje, zakaj internacionalizirati visokošolsko dejavnost (de Wit, 2002; de Wit, 2011), s tem pa pogojujejo tako dojemanje, kaj pomeni internacionalizacija visokega šolstva, kot tudi način oblikovanja njenih politik in strategij ter njihovo skladnost z glavnimi nameni visokošolskega izobraževanja.

Motivi za internacionalizacijo visokega šolstva so namreč v Sloveniji bolj politično kot gospodarsko naravnani, medtem ko se na Nizozemskem mednarodne študente, ki plačujejo šolnine, dojema kot ključne za ustvarjanje konkurenčne prednosti nizozemske ekonomije znanja na globalni ravni. Ker je tudi v mnogih drugih državah (EVP) ustvarjanje prihodkov pomemben argument za rekrutiranje mednarodnih študentov (de Wit, 2012; de Wit et al., 2015), to razodeva "[p]aradoksalno kombinacijo med sodelo- 
vanjem in konkurenco kot prevladujočima motivoma internacionalizacije /.../ v okviru bolonjskega procesa « (Bologna Process Researchers' Conference, 2017: 5).

Vplivi raznolikih geopolitičnih, ekonomskih, zgodovinskih in družbeno-kulturnih okoliščin torej ustvarjajo tako priložnosti kot izzive za dohodno in odhodno, dolgoročno in kratkoročno mobilnost med in znotraj posameznih oddelkov, institucij, držav in svetovnih regij. Zato

[b]i bilo preveč preprosto trditi, da se v evropskem visokem šolstvu spreminjajoča se pokrajina internacionalizacije $\mathrm{v}$ smeri večje konkurenčnosti in aktivnega rekrutiranja mednarodnih študentov iz Evrope in zunaj nje razvija na podoben način. Obstajajo različni poudarki in pristopi. Strategije internacionalizacije so /.../ kontekstualizirane s specifičnim notranjim kontekstom univerze in njeno nacionalno vpetostjo. (de Wit, 2012: 436)

V Sloveniji, na Nizozemskem in tudi v širšem območju EVP-ja so namreč prisotne precejšnje razlike med visokošolskimi zavodi, kar zadeva delež mobilnih študentov, saj nekateri poročajo, da mednarodni študenti predstavljajo več kot desetino celotne študentske populacije, na veliki večini visokošolskih ustanov pa je njihov odstotek (znatno) nižji (European University Association (EUA), 2013). V svojem vključevanju v mednarodno okolje se namreč srečujejo $\mathrm{z}$ različnimi omejitvami kot tudi s številnimi možnostmi in priložnostmi za njihovo delovanje. Na ta način se prilagajajo svetu, v katerem obstajajo raznolike možnosti odnosa med njihovim mednarodnim, nacionalnim, institucionalnim in disciplinarnim razvojem visokega šolstva, $s$ tem pa tudi študentske mobilnosti.

\section{Literatura}

Bolonjska deklaracija (1999). http://archive-2010-2015.e.eaa.info/article-details.aspx?ArticleId $=80$ (2. 12. 2019).

Bologna Process Researchers' Conference (2017). Future of higher education Bologna Process researchers' conference: Conference report. http://www. ehea.info/cid1180o6/bologna-process-researchers-conference.html (29. 11. 2019).

De Wit, Hans. "Student mobility between Europe and the rest of the world: Trends, issues and challenges«. V European Higher Education at the crossroads: Between the Bologna Process and national reforms, ur. Adrian 
Curaj, Peter Scott, Lazăr Vlasceanu in Lesley Wilson, 431-439. Dordrecht: Springer, 2012.

De Wit, Hans, Fiona Hunter, Laura Howard in Eva Egron-Polak. Internationalisation of higher education. Brussels: European Parliament, Directorate-General for Internal Policies, 2015.

DiMaggio, Paul J. in Powell, Walter. »The Iron Cage Revisited: Institutional Isomorphism and collective Rationality in Organizational Fields«. American Sociological Review, 48, št. 2 (1983): 147-160.

DiMaggio, Paul J. in Powell, Walter. »Introduction«. V The New Institutionalism in Organizational Analysis, ur. Walter Powell in Paul J. DiMaggio, 1-38. Chicago: University of Chicago Press, 1991.

Dobbins, Michael. Comparing Higher Education Policies in Central and Eastern Europe: To converge or not to converge? (Doktorska disertacija). Konstanz: Universität Konstanz, 2018.

European Commission (2013). European higher education in the world. https:// ec.europa.eu/education/policy/international-cooperation/world-education_en (25.11. 2019).

European Commission. Erasmus+ annual report 2016: Statistical annex. Brussels: European Commission, 2017.

European Commission, EACEA in Eurydice. The European Higher Education Area in 2018: Bologna Process implementation report. Luxembourg: Publications Office of the European Union, 2018.

European University Association (EUA). Internationalisation in European higher education: European policies, institutional strategies and EUA support. Brussels: EUA, 2013.

Evropska komisija. Sporočilo Komisije Evropskemu parlamentu, Svetu, Evropskemu ekonomsko-socialnemu odboru in Odboru regij: Evropsko visokošolsko izobraževanje v svetu. Bruselj: Evropska komisija, 2013.

Hall, Peter A. in Taylor Rosemary C. R. »Political Science and the Three New Institutionalisms«. Political Studies, 44, št. 5 (2011): 936-957.

Hauptman Komotar, Maruša. Internacionalizacija in zagotavljanje kakovosti $v$ visokem šolstvu $v$ Sloveniji in na Nizozemskem (Doktorska disertacija). Ljubljana: Pedagoška fakulteta Univerze v Ljubljani, 2018.

Klemenčič, Manja in Alenka Flander. Evalvacija učinkov programa Erasmus na visoko šolstvo v Sloveniji. Ljubljana: CMEPIUS, 2013.

Knight, Jane. Higher education in turmoil: The changing world of internationalisation. Rotterdam: Sense Publishers, 2008. 
Leuven Communiqué (2009). http://archive-2010-2015.ehea.info/article-details.aspx?ArticleId=80 (7. 1. 2020).

Meyer, John W., Boli, John, Thomas, George M. in Ramirez, Francisco O. »World Society and the Nation State«. American Journal of Sociology, 103, št. 1 (1997): 144-181.

Ministry of Education, Culture and Science (2014). Into the world: Letter on the government's vision on the international dimension of higher education and VET. https://www.government.nl/government/members-of-cabinet/ jet-bussemaker/documents/letters/2014/o7/21/government-s-vision-on-the-international-dimension-of-higher-education-and-vet (10. 11. 2019).

Ministry of Education, Culture and Science. The value of knowledge: Strategic agenda for higher education and research 2015-2025. The Hague: Ministry of Education, Culture and Science, 2015.

Ministrstvo za izobraževanje, znanost in šport (2016). Strategija internacionalizacije slovenskega visokega šolstva 2016-2020. https://www.cmepius.si/ wp-content/uploads/2014/o2/Strategija-internacionalizacije-slovenskega-visokega-solstva-SLO-2016\%E2\%80\%932020_WEB.pdf (3. 12. 2019).

Ministrstvo za izobraževanje, znanost in šport (2019). Akcijski načrt Strategije internacionalizacije slovenskega visokega šolstva (2018-2020). https:// www.gov.si/teme/internacionalizacija-visokega-solstva/ (3. 12. 2019).

Ministrstvo za šolstvo, znanost in šport (2002). Nacionalni program visokega šolstva. http://www.pisrs.si/Pis.web/pregledPredpisa?id=NACP 33 (4. 12. 2019).

Ministrstvo za visoko šolstvo, znanost in tehnologijo (2011). Resolucija o nacionalnem programu visokega šolstva 2011-2020. http://www.drznaslovenija.mvzt.gov.si/cho1.html (5.12. 2019).

Nuffic (2019a). Incoming degree student mobility in Dutch higher education 2018-2019. https://www.nuffic.nl/en/publications/incoming-degree-student-mobility-dutch-higher-education-2018-2019/ (6. 1. 2020).

Nuffic (2019b). Facts and figures. https://www.nuffic.nl/en/subjects/facts-and-figures/ (6. 1. 2020).

OECD. Education at a glance: OECD indicators. Paris: OECD, 2017.

Paris Communiqué (2018). http://www.ehea2018.paris/Data/ElFinder/s2/ Communique/EHEAParis2018-Communique-final.pdf (23. 12. 2019).

SURS (2019). Tuji študenti visokošolskega študija po državi državljanstva, Slovenija, 2018/19 (interno gradivo). Ljubljana: SURS. 
Sursock, Andrée. Trends 2015: Learning and teaching in European universities. Brussels: EUA, 2015.

Teichler, Ulrich. »Internationalising higher education: Debates and changes in Europe«. V Changing educational landscapes, ur. Dimitris Mattheou, 263-283. Dordrecht: Springer, 2010.

Teichler, Ulrich, Irina Ferencz in Berndt Wächter (ur.). Mapping mobility in European higher education (Vol. I). Brussels: European Commission, 2011.

UNESCO Institute for Statistics. (2019). Global flow of tertiary-level students. http://uis.unesco.org/en/uis-student-flow

Univerza v Ljubljani (2014). Strategija internacionalizacije Univerze $v$ Ljubljani 2014-2017 (2020). https://www.uni-lj.si/o_univerzi_v_ljubljani/strategija_ul/ (12.12. 2019).

Univerza na Primorskem (2014). Srednjeročna razvojna strategija UP 2014 2020. https://www.famnit.upr.si/sl/resources/files/o-fakulteti/poslanstvo-in-vizija/upsrednjrazvojnastrat2014-2020.pdf (12 (12. 12. 2019).

University of Twente (2015). 2020: Educating the global citizen. https://www. utwente.nl/en/vision2020/achievements/internationalization/archive-internationalization/update-internationalization/ (15. 12. 2019).

Vaira, Massimiliano (2004). »Globalization and higher education organizational change: A framework for analysis«. Higher Education, 48, št. 4 (2004): 483-510.

Van Gaalen, Adinda, Hendrik Jan Hobbes, Sjoerd Roodenburg in Renate Gielesen. Management summary: Internationalising students in the home country. The Hague: Nuffic, 2014.

VSNU in VH (2014). Internationalization vision. https://www.vsnu.nl/files/documents/Publications/Internationalization_vision.pdf (15. 12. 2019).

Working Group on Mobility (2012). Mobility for better learning: Mobility strategy 2020 for the European Higher Education Area (EHEA). https://www. ehea.info/cid101043/ministerial-conference-bucharest-2012.html (10. 12. 2019).

Zakon o spremembah in dopolnitvah zakona o visokem šolstvu (1999). Uradni list RS, št. 99/1999.

\section{Seznam intervjujev}

Intervju s predstavnikom Nizozemske organizacije za mednarodno sodelovanje (Nuffic) - Intervju 1 (30. maj 2016). Intervju opravil M. Hauptman 
Komotar [zvočni posnetek]. Internacionalizacija v nizozemskem visokem šolstvu. [Doktorska disertacija] (I4-NIZ). Osebni arhiv, Litija.

Intervju s fakultetnim koordinatorjem za internacionalizacijo v visokem šolstvu - Intervju 2 (31. maj 2016). Intervju opravil M. Hauptman Komotar [zvočni posnetek]. Internacionalizacija v nizozemskem visokem šolstvu. [Doktorska disertacija] (I5-NIZ). Osebni arhiv, Litija.

Intervju z ekspertom za področje internacionalizacije visokega šolstva - Intervju 3 (20. junij 2016). Intervju opravil M. Hauptman Komotar [zvočni posnetek]. Internacionalizacija v nizozemskem visokem šolstvu. [Doktorska disertacija] (I7-NIZ). Osebni arhiv, Litija.

Intervju $\mathrm{z}$ ekspertom za področje internacionalizacije in zagotavljanja kakovosti v slovenskem visokem šolstvu - Intervju 4 (29. junij 2016). Intervju opravil M. Hauptman Komotar [zvočni posnetek]. Internacionalizacija in zagotavljanje kakovosti v slovenskem visokem šolstvu. [Doktorska disertacija] (I9-SLO). Osebni arhiv, Litija.

Intervju s predstavnikom Ministrstva za izobraževanje, znanost in šport Intervju 5 (7. september 2016). Intervju opravil M. Hauptman Komotar [zvočni posnetek]. Internacionalizacija in zagotavljanje kakovosti v slovenskem visokem šolstvu. [Doktorska disertacija] (I14-SLO). Osebni arhiv, Litija. 